\title{
Space Technology, an Essential Infrastructure for Rural Area Development
}

\section{Onuh Spencer Ojogba, Aiyeola Sikiru Yommy, Tofade Temidayo Christopher, Linda Ojone Adesina}

Centre for Satellite Technology Development, National Space Research and Development Agency, Abuja, Nigeria

\section{Email address:}

sonuh@hotmail.com (O.S. Onuh), aiyeolasikiru@gmail.com (S. Y. Aiyeola), tofadetemi-dayo_2006@yahoo.com (T. C Tofade), linlona@gmail.com (L. O. Adesina)

\section{To cite this article:}

Onuh Spencer Ojogba, Aiyeola Sikiru Yommy, Tofade Temidayo Christopher, Linda Ojone Adesina. Space Technology, an Essential Infrastructure for Rural Area Development. American Journal of Environmental and Resource Economics. Vol. 4, No. 1, 2019, pp. $25-31$. doi: 10.11648/j.ajere.20190401.13

Received: January 14, 2019; Accepted: March 1, 2019; Published: March 21, 2019

\begin{abstract}
Over the past five decades, space technology has been regarded as either the dream and future of mankind or an endeavor of the Cold War space race. Neither of these views is relevant today. The essential role space serves today is that it is a critical infrastructure for the world. Space is no longer the "big boys club". Today, about 60 countries own and operate at least one satellite, and almost everyone benefits from the services these satellites provide. Space technology has become an indispensable infrastructure on which everyone relies. Space technology has the capabilities to provide information vital for the environment, education, food security, public health, water resource management, human rights, disaster relief and nuclear security. Services derived from this technology not only improve the efficiency and effectiveness of many terrestrial activities but also provide much of the information and understanding needed to prevent and mitigate a variety of risks. Space-based technologies are embraced in developing countries and some of the applications are rooted in education. This was not so in the past, as the technologies were considered ancillary tools for only wealthy nations. Space technology includes the spacecraft otherwise known as satellite, space stations, other supporting infrastructure, equipment, and procedures. The development of space technology can play significant roles in the development of rural areas in Nigeria. The areas of application include, education, telemedicine, agriculture, and communication. This paper focuses on the use of space technology in the development of rural areas.
\end{abstract}

Keywords: Space Technology, Infrastructure, Telemedicine, Agriculture, Communication, Rural Areas

\section{Introduction}

Space technology includes the spacecraft otherwise known as satellite, space stations, other supporting infrastructure, equipment, and procedures. The development of space technology can play significant roles in the development of rural areas in Nigeria. The areas of application include; education, telemedicine, agriculture, communication, security, disaster management, and remote sensing. Rural area dwellers, especially in developing countries are faced with what is called "digital divide" which shows the inequalities between those with and those without access to developmental resources. Space-based infrastructure is used to bridge this gap. They increase access to resources everywhere, thereby connecting the rural areas [1]. Adequate supply of infrastructure to rural areas is believed to make life more meaningful to rural dwellers. Space technology provides infrastructure that bring development to the people of rural areas. Satellites launched into space are infrastructures that rapidly accelerate growth and this leads to economic advancement. Nowadays, the World Wide Web and the Internet have come to stay as what individuals in rural areas cannot do without as this makes information of all kinds available when they are needed. The developments of e-services such as e-learning, and e- culture, are gradually becoming global realities. Cultural and educational organizations and institutions now have the opportunity of providing on-demand cultural and educational information to Internet users [2]. In rural areas, where there is no terrestrial communications infrastructure, space technology provides reliable and robust way of delivering high data rate and voice communication services. Very small aperture terminals 
(VSATs) are used to connect wireless repeater stations which in turn connect customers in coverage areas [3]. Today, the world is dependent on information and communication technologies (ICT) where rural areas get connected to the information high way. Communication satellites are playing vital roles by contributing to the global information infrastructure, thereby meeting the communications needs of people, governments and businesses. The remaining part of the paper contains discussions on the use of space technology in the development of rural areas. The discussions are on tele-education, telemedicine, agriculture, communication, disaster management and lastly e-governance.

\section{Space Technology in Rural Areas}

\subsection{Tele-education}

In 1980 the U.S. Agency for International Development initiated the AID Rural Satellite Program (RSP) to explore the potential of telecommunications as a means of extending scarce expert resources and expanding educational opportunities to remote and rural areas [4]. There is no doubt that the world today has become increasingly dependent on information and communication technologies (ICT) and with it comes the need for societies and communities to stay connected and be integrated into the global information super highway. Communication Satellites today have become an integral part of global information infrastructure, connecting people across the world and serving communications needs of individuals, businesses and governments. Distance learning is a very useful and promising application of satellite-based technology. With this, high-quality educational institutes can share their resources with their counterparts that are underserved and this can be used to train the trainers. The train the trainer programme via space technology is to ensure that teachers in the remote areas have access the tools, curricula and the necessary assistance they need. Figure 1 depicts the links from satellite the teaching end, class rooms 1 and 2.

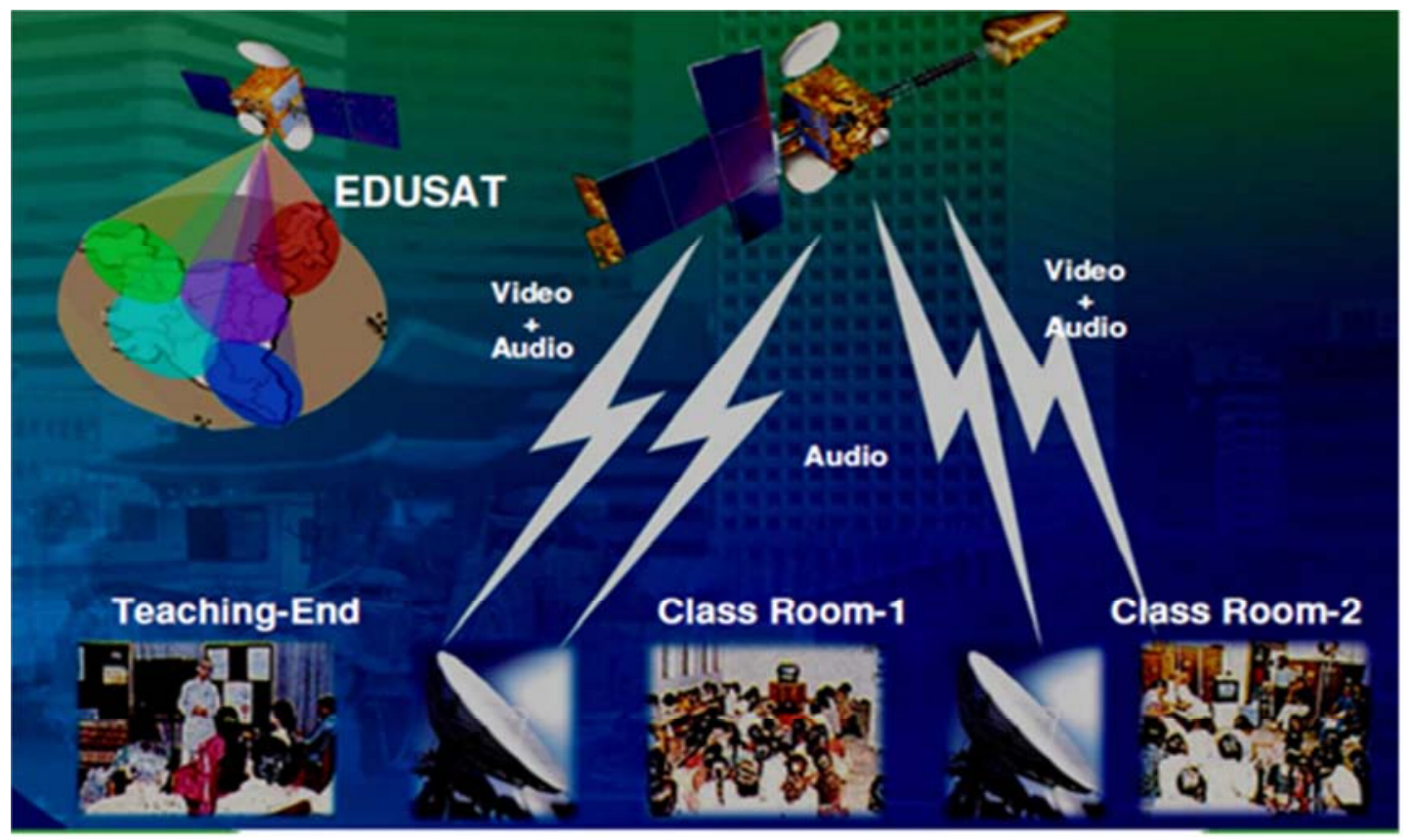

Figure 1. Tele-education concept [5].

Composition of tele-education network

The Edusat is an example of satellites used for tele-education. It is a satellite owned by Indian and it was launched to exclusively serve the educational sector in India. The tele-education network makes it possible for data to be transferred from the teaching end to remote classrooms. The data transferred include lecture notes, presentation materials, exercises, courseware, and other component needed to make learning effective [6]. It comprises the following:

A. Spacecraft

The spacecraft is the satellite launched for educational purposes. The satellite is used to provide virtual classroom concept to provide education to children in rural and remote areas. This concept is also employed to offer quality higher education to students in areas without access to good technical institutes, and adult learning programmes and training modules for teachers. The satellite could be equipped with $\mathrm{Ku}, \mathrm{Ka}$, C-band and other frequency-band transponders.

B. Teaching end

The teaching end consists of an earth station and a small studio. In the studio, recorded and live lectures can be found and it is linked to the uplink earth station. The lectures, which are audio signals and visual images are transmitted to the spacecraft (satellite). The satellite beams the transmitted signal back to the earth spanning a large geographical area. The presentation PC, digital camera and DVD player are all attached to a switcher which is used to select the signal of interest among those from the presentation PC, digital camera and DVD player. The PC used by the presenter has a digital monitor that is used as a "white board". The teacher can use 
digital pen to draw pictures and write texts on the white board and whatever the teacher writes at his end can be transmitted to the students end. A microphone is directly attached to server. The mixed output that is, the audio and video is sent to the modem through server. The modem then converts the digital inputs to analog and sends it to antenna using high quality cables.

C. Remote classrooms

In the classrooms live lectures are received. We have two types of classrooms-non-interactive and interactive. At the location of the classrooms, receiving antennas are installed. The antenna installed at the non-interactive classroom has receive-only capability and the students can only interact with the resource person via a telephone line, internet and mobile phones. In the case of interactive classroom, the students can interact with the resource person at the teaching end using voice link via the satellite using an audio return channel [6]. The use of satellite for tele-education is also illustrated using Figure 2.

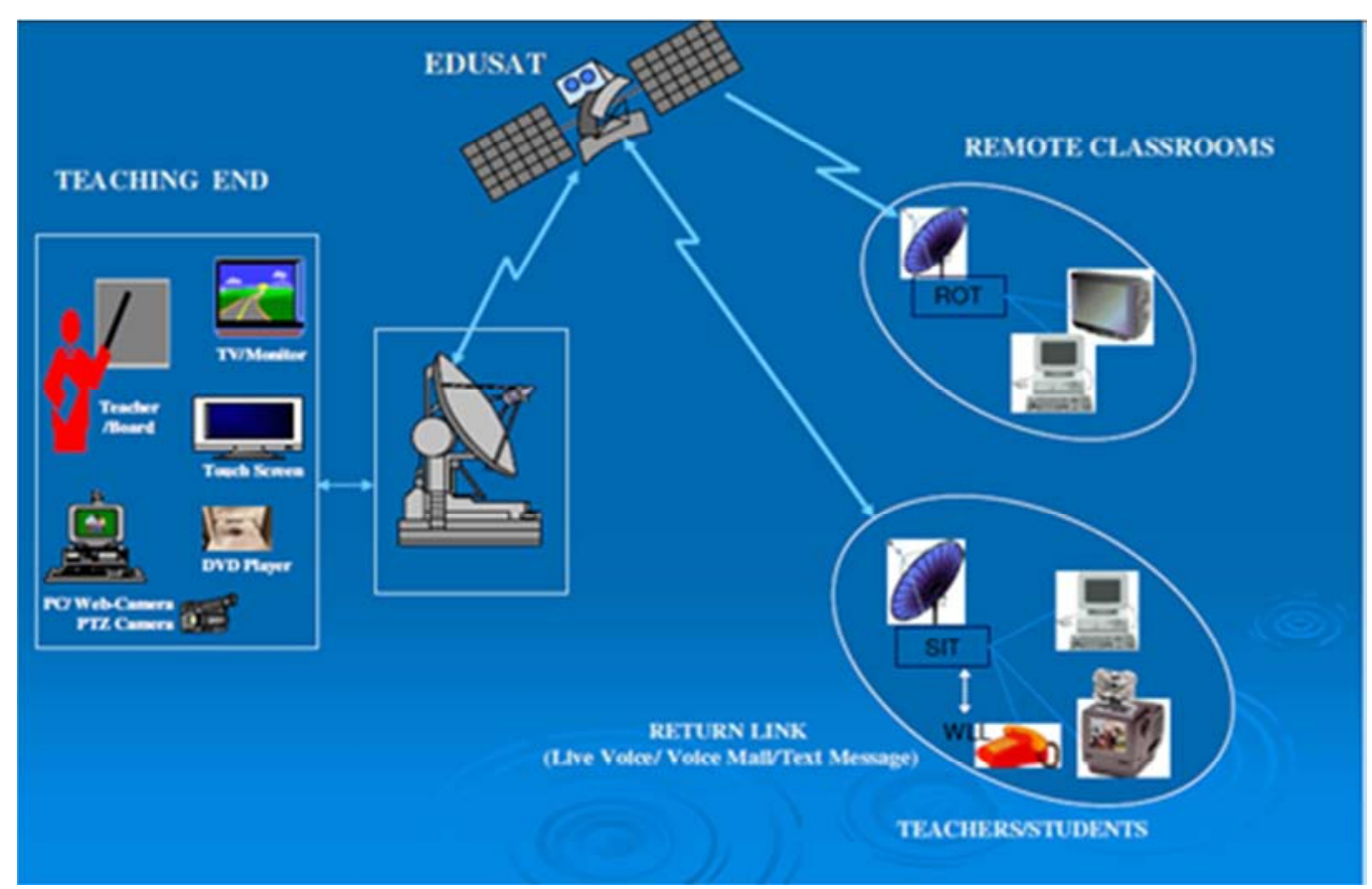

Figure 2. Tele-education concept [7].

\subsection{Satellite-Based Telemedicine}

Telemedicine is referred to as the delivery of healthcare services by healthcare professionals employing information and communication technologies for the transfer and exchange of relevant information required for prevention, diagnosis, and treatment of injuries and diseases, and for continually educating healthcare providers [8]. Innovative healthcare technology and delivery methods are required for the provision of high-quality healthcare for low density population areas. Space technology provides such solution. Space technologies have had tremendous impact in human health. Space resources, such as GIS and communication satellites make it possible to deliver remotely healthcare services to rural areas [9]. Telemedicine provided by satellites in space, scientific research, geographical information systems (GIS), and space spin-offs are providing new ways to improve human health in rural areas. Telemedicine is the use of two-way telecommunications technology, multimedia and computer networks that is used to enhance and deliver healthcare.

Space technology makes it possible for medical researches to be conducted. The microgravity environment available in space is an example of excellent laboratory. In space, microbes and cells behave differently, hence monitoring reaction and processes in space in the absence of gravity variable has the advantage of giving a better understanding of infectious diseases [9]. Rural areas lack adequate number of experienced doctors. Space-based telemedicine can remove the healthcare divide between rural and urban dwellers [10]. Connecting rural hospitals to the world medical centres requires the provision of high speed internet connection Very Small Aperture Terminal (VSAT), fibre optics and so on to rural hospitals. The Very Small Aperture Terminal link may have the following hardware specifications:

i. Indoor unit: Comprises of IP based satellite modem, and a personal computer

ii. Outdoor units: Comprises of Radio Frequency (RF) Transmitter and a satellite dish antenna of required diameter depending on the operating frequency band and other hardware.

There are two possible configurations for the VSAT connection:

A. Point-to-point connection

In this configuration, the VSAT provides network connection between the server and the client computer and static IP addresses are assigned to the server and client computers. This configuration is depicted in Figure 3: 


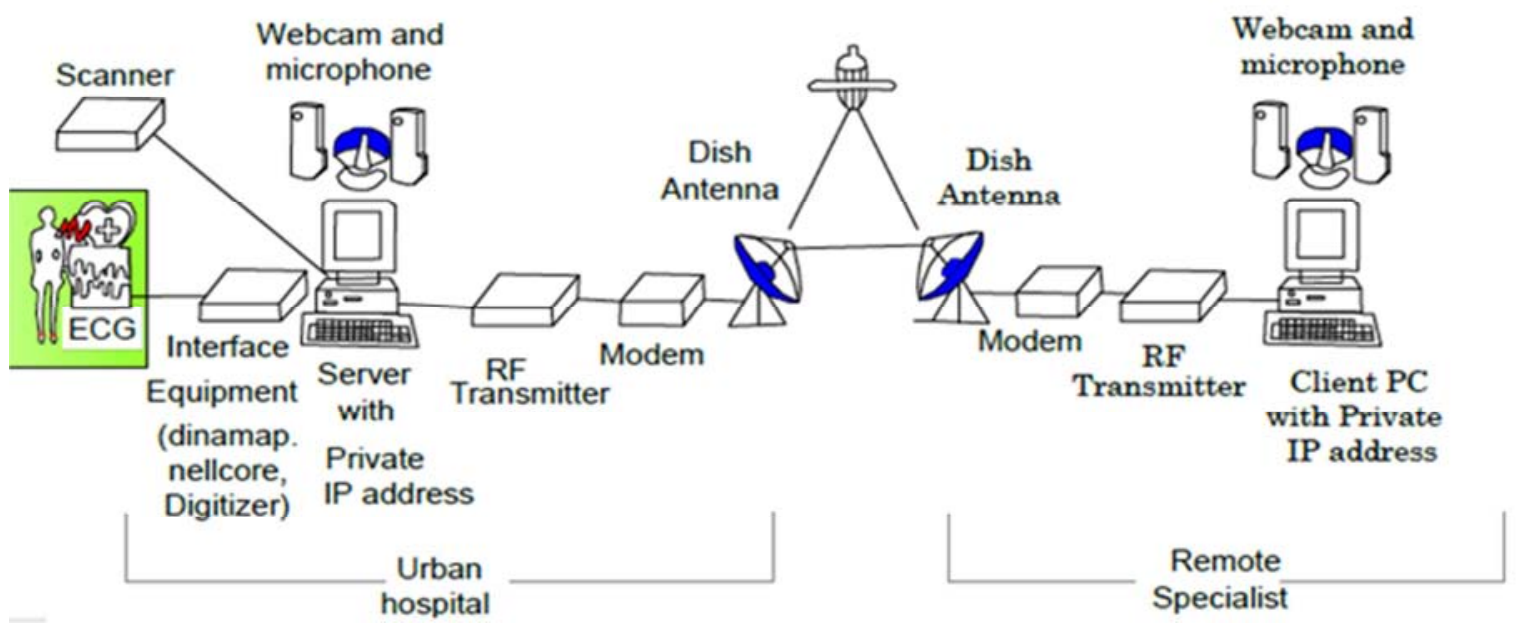

Figure 3. Point to point connection using VSAT [10].

B. Point-to-multipoint connection

In the point-to-multipoint configuration, the VSAT provides Internet connection for the PC with public IP address. This configuration has the advantage of connecting to any consultation hospital or specialist which are connected to the Internet. Figure 4 is used to depict this configuration:

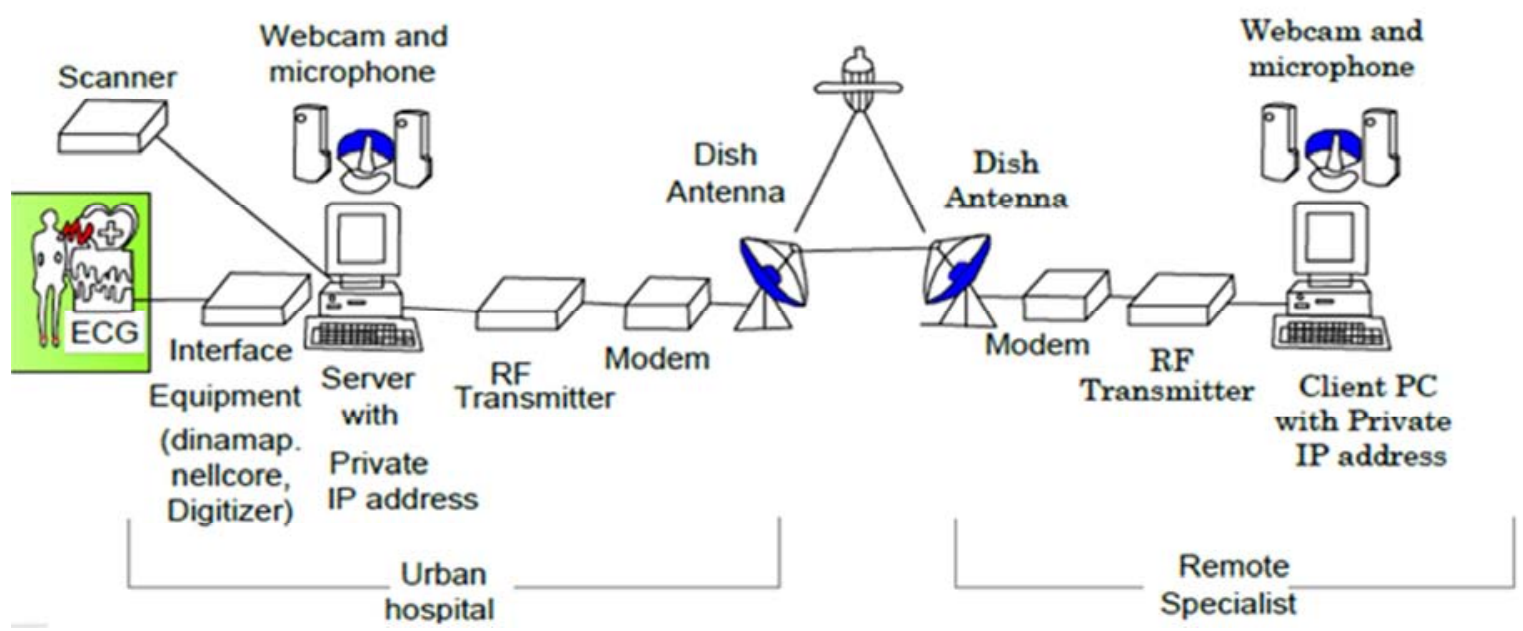

Figure 4. Point to multi point connection using VSAT.

\subsection{Agriculture}

Agriculture is the basis for the world's food supply. Availability of water, soil and weather conditions, climate change and so on can be of great challenges to both the farmers and the entire food security to the entire populace. To enhance profitability and production, space technology is a good asset to food manufacturers, and farmers. Important data required for monitoring snow cover, soil, crop development, and drought. Assessment of rainfall using satellites can help farmers plan the timing and quantity of irrigation they would need for their crops. Accurate analysis and information can also help farmers to predict the agricultural outputs of a region early enough and can be critical in anticipating and mitigating the effects of famine and food shortage [11]. Figure 5 shows the application of space technology to agriculture.

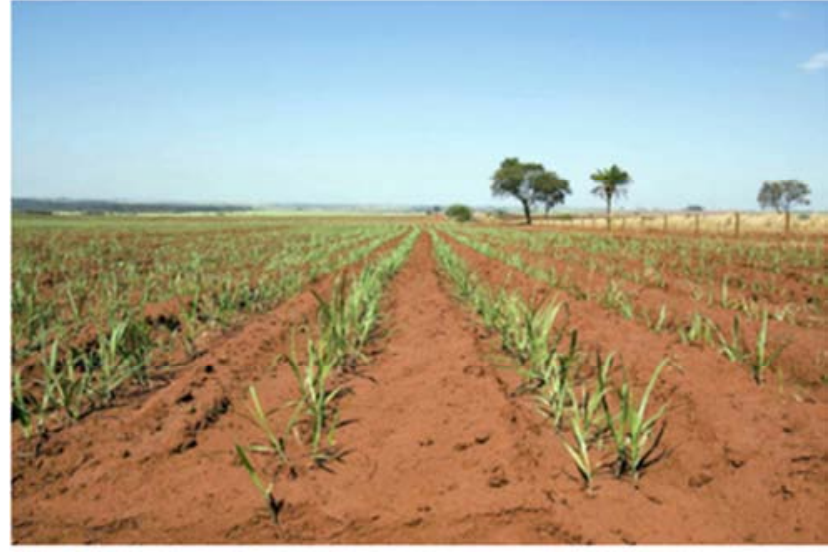

Figure 5. Application of space technology to agriculture.

\subsubsection{Desertification}

Sustainable land use is a requirement for lifting millions of 
people out of poverty, and this enables nutrition and food security and also safeguards water supplies. Desertification includes land degradation in arid, semi-arid, and dry sub-humid areas which is as a result of factors such as human activities such as over cultivation, over grazing. This phenomenon affects up to one-sixth of the world's population. Sustainable development goal 16 of the United Nations Conference is aimed at tackling desertification and restoring degraded soil and land, which includes land that had suffered desertification, floods and drought. This aims at achieving land degradation-free world by the year 2020 .

To solve the problem of desertification, space technology can offer significant advantages in terms of homogeneity and spatial and temporal coverage of observations and the technology allows monitoring of various elements of desertification processes. These elements include surface temperature vegetation indices, moisture, changes in vegetation cover, land surface composition, sand and wind transportation and so on. Desertification is a complex, environmental problem caused by multiple factors, its monitoring therefore requires the integration of both human and environment-based variables. Since it is essential for early warning and monitoring of desertification development and its extent, remotely sensed information also assists in evaluating the effects of policies to combat desertification. The Figure 6 below shows the effect of a dry land as a result of desertification [12]. Dry land as a result of desertification is depicted in Figure 6.

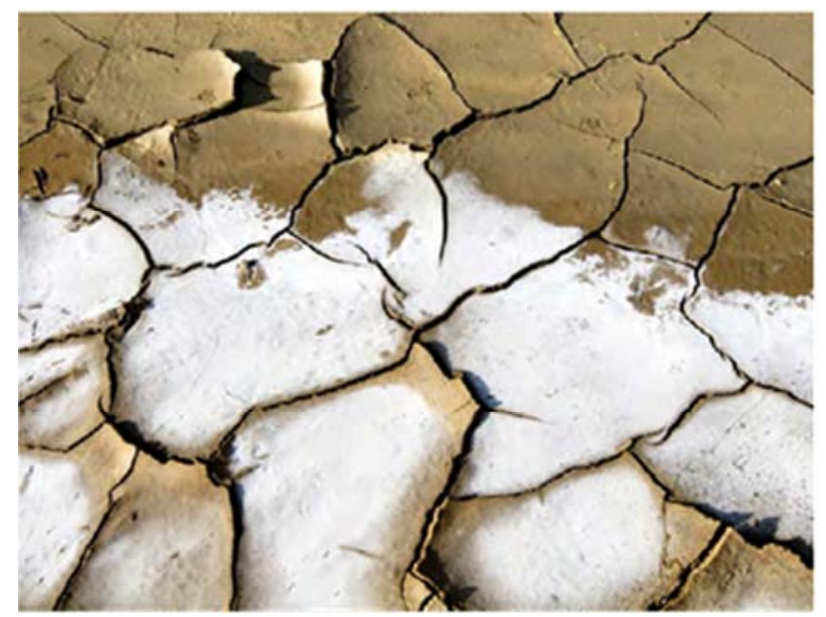

Image: UN Photo/Martine Perret

Figure 6. Dryland in Timor-Leste.

\subsubsection{Drought}

Forecasting of drought and its early detection relies on the availability of satellite imaging systems. This makes it possible for decisions to be taken to prevent the occurrence and mitigate the effects of drought. Monitoring of drought that is based on knowledge acquired an from archived imagery can help profile current trends and occurrence so as to mitigate the effects of drought and this can help avoid drought in rural areas [12]. Figure 7 shows the part of a village affected by drought.

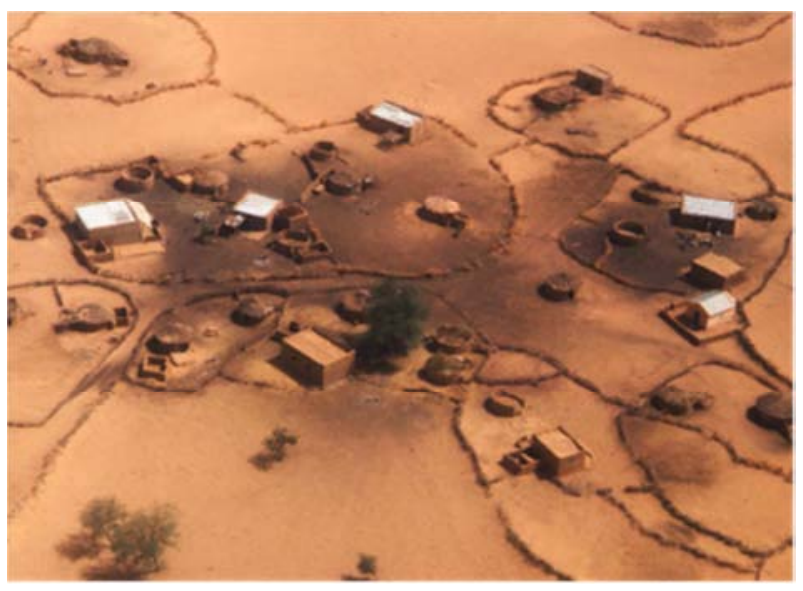

Image: UN Photo/John Isaac

Figure 7. Mauritian village affected by drought.

\subsection{Communication}

Information sharing is one of the ways people interact. This is peculiar to both the rural and urban dwellers. Information sharing is done using personal computers, mobile phones and other electronic communication devices. Space-based technologies enables communication to be extended to rural area with the use of communications satellites, which makes global telecommunications possible by relaying signals in form of audio, video, and data to and from one or more locations. Space-based technologies can reduce the cost of ground-based infrastructure requirements and even offer cost effective options for service delivery. For instance, installation of a large number of signal transmitting and relaying towers to broadcast television programmes to distant locations may not be necessary when space-based communication is used. To achieve this, one satellite dish could be installed in a rural area to pick up the broadcast signal received from a satellite [13]. Example of communications using space-based technology is depicted in Figure 8.

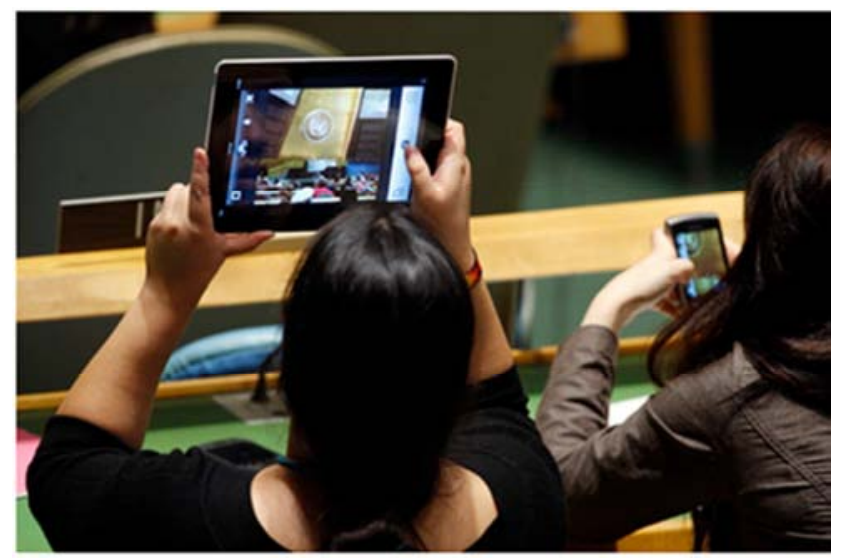

Figure 8. Space-based communication using mobile devices.

\subsection{Disaster Management}

Disaster is referred to as a disruption to the functioning of a society. Disaster causes material, economic, environmental, 
and human losses which exceed the ability of the society to cope with its own available resources. Cases of hurricanes, floods, earthquakes, landslides, wildfires, and other disasters have been recorded. Disaster management is used to reduce the impacts of disasters, thereby minimizing loss of life and property. Before the occurrence of a disaster, data obtained from remote sensing can be used to predict disaster and provide early warning to rural dwellers. When ground-based infrastructure is damaged, satellite becomes a reliable infrastructure that can be used to provide communication for disaster management [14]. Flood as an example of disaster is shown in Figure 9.

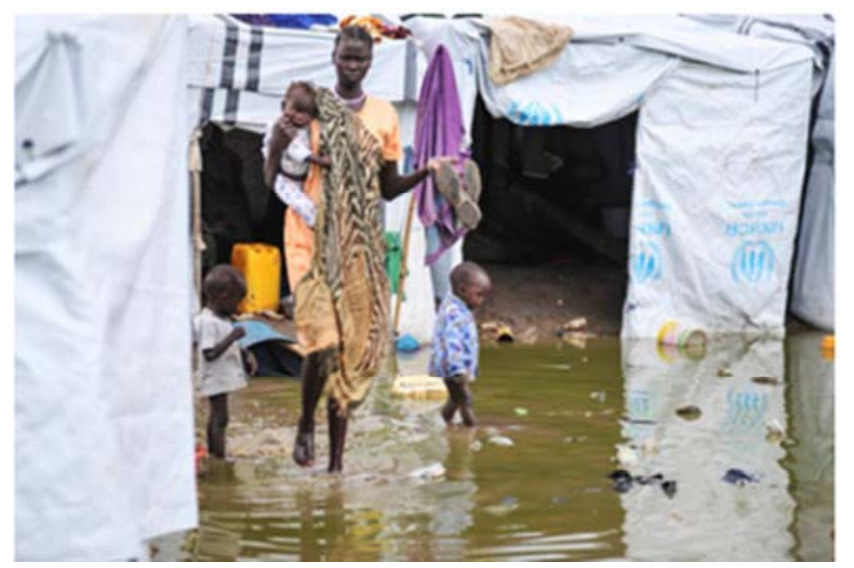

Figure 9. Flood as an example of disaster [14].

\section{6. e-Governance}

The European Union defines e-governance as "the use of Information and Communication Technologies in public administrations combined with organizational change and new skills in order to improve public services and democratic processes." [15]. It is now common in the world today, that Governments embrace Information and Communication Technologies (ICT) through what is called e-governance to improve service delivery, wider reach, and transparency. However, rural settlements lacking the required ICT infrastructure are left behind. Communication satellite, which are space assets are used to provide these services [16]. Communication Satellites have competitive advantages as they are used to complement the sparsely distributed terrestrial link such as fiber optics and radio link extensions thereby contributing to rapid economic growth, socio-economic growth, transparent process through e-governance, and secure communications for use by security agencies [17]. Figure 10 shows some of the uses of the Nigerian Communications Satellite-1R (NigComSat-1R) providing broadband Internet access and connectivity in Nigeria and Africa as a whole. E-Governance is for development and it covers the following areas:

i. Connecting citizens: e-citizens and e-services

ii. Improving government processes: e- administration

iii. Building interactions with and within civil society: e-society [18].

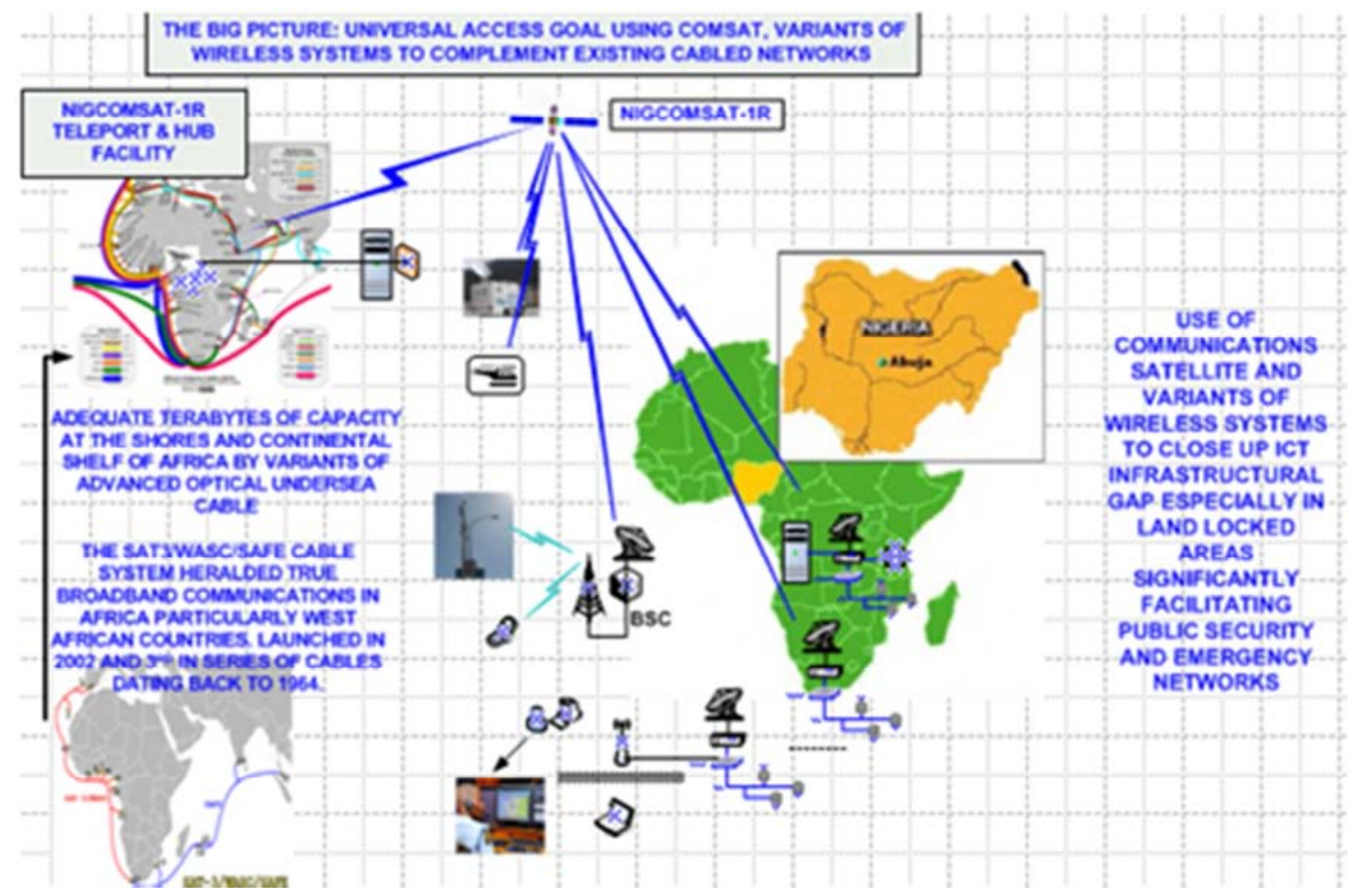

Figure 10. Broadband Internet access and connectivity in Nigeria and Africa form NigComSat-1R.

\section{Conclusion}

In this paper, we have focused on the use of space tech- nology for rural area development. The paper has demonstrated that space technology is a vital infrastructure in rural areas development. Space technology can serve as a tool to complement the grossly inadequate terrestrial infrastructure 
and this will attract investors to those areas and rapid development will take place. Considering the myriad applications of space technology, it is therefore important for Government world over to invest in space technology to reduce the migration of rural dwellers to urban areas. There is no doubt that space technology is well placed as an essential infrastructure to contribute new types of information and communication tools to form part of the solution to the major challenges facing rural area development today.

\section{Acknowledgements}

We sincerely appreciate the support of management and entire staff of the National Space Research and Development Agency (NASRDA) for the support and encouragement from them towards the success of this work.

\section{References}

[1] Kazuto S. C, "Global Agenda Council on Space Security." by the World Economic Forum's Global Agenda Council on Space Security 2012-2014, pp. 1-52.

[2] Athanasios S. D, Member, Yannis V. P, and Dimos G. A, "A Real Time Satellite Network for E-Culture Applications." IEEE EUROCON Conference, Serbia \& Montenegro, Belgrade, November 22-24, 2005, pp. 1-4.

[3] Amir I. Z, Ozlem K, Luiz A. D, and Scott F. M, "Satellite-Based Assured Communications for Critical Mobile Network Infrastructure." 2009 IEEE Antennas and Propagation Society International Symposium, pp. 1-4.

[4] Shaw W. D, "Distance Education via Satellite: A Case Study of the Indonesian Distance Education Satellite System." Online Journal of Space Communication.

[5] Radhakris D, "Space Technology for Education." Indian Space Research Organisation.

[6] Mamta G and Manoj K, "Edusat-E-learning through satellite-reaching the unreached." International Journal of Recent Trends in Engineering, Vol 1, No. 2, May 2009, pp. 1-3.

[7] Sohanvir C and Suresh G, "On using satellite-based networks for capacity building and education for all: A case study of Rajiv Gandhi project for EduSat-supported elementary education" Educational Research and Reviews Vol. 5 (4), April 2010, pp. 158-168.
[8] Carlo C, Gabriele P, and Giuseppe P, "Telemedicine for Developing Countries.” Applied Clinical Informatics, 2016,. pp. $1-26$.

[9] Kazuto S, "Bringing Space Down to Earth." Global Agenda Councils, A Community of the World Economic Forum, 2015, pp.1-52.

[10] Jabir S. A, Osama A. H and Amer N, "Design of Telemedicine Systems for Rural and Urban Areas in Iraq." Asian Research Publishing Network (ARPN) Journal of Engineering and Applied Sciences, (C2006-2009, pp. 64-72.

[11] United Nations office of Outer Space Affairs, "Benefits of Space: Agriculture." 2012, Available at: www.unoosa.org/oosa/en/benefits-of-space/agriculture.html.

[12] Simonetta D. P, "Space for Agriculture Development and Food Security: Use of Space Technology within the United Nations System."

[13] United Nations office of Outer Space Affairs, "Benefits of Space: Communication." 2012, Available at: www.unoosa.org/oosa/en/benefits-of-space/communication.ht $\mathrm{ml}$.

[14] United Nations office of Outer Space Affairs, "Benefits of Space: Disaster Management." 2012, Available at: www.unoosa.org/oosa/en/benefits-of-space/disaster management.html.

[15] Grönlund, A, "Introducing e-GOV: History, Definitions and Issues." Communications of the Association for Information Systems, 2004, pp. 713-729.

[16] "Role of Communication Satellites in Socio-Economic Development." Available at:

http://www.suparco.gov.pk/downloadables/11-Role-of-Satellit es-in-Socio-Economic-Development.pdf, pp. 1-3.

[17] Lawal L. S, Ahmed-Rufai. T., Chatwin C. R, and Liu. R, "The Role of Communication Satellites in Public Management, Education, Governance and Business in Nigeria." Human Resource Management Research 2013, 3(5): 178-187 DOI: 10.5923/j.hrmr.20130305.02, pp. 1-10.

[18] Richard. H, "Understanding e-Governance for Development." Published with the support of The Commonwealth Network of Information Technology for Development, ISBN: 1902518934 , 2001, pp. 1-27. 